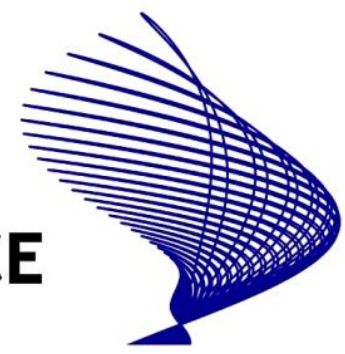

NORFACE MIGRATION Discussion Paper No. 2011-5

\title{
The Nexus between Labor Diversity and Firm's Innovation
}

Pierpaolo Parrotta, Dario Pozzoli and Mariola Pytlikova 


\title{
The Nexus between Labor Diversity and Firm's Innovation*
}

\author{
Pierpaolo Parrotta ${ }^{\dagger}$ Dario Pozzoli ${ }^{\ddagger}$ and Mariola Pytlikova ${ }^{\S}$
}

January 6, 2011

\begin{abstract}
In this paper we investigate the nexus between firm labor diversity and innovation using a linked employer-employee data from Denmark. Specifically, exploiting information retrieved from the comprehensive database and implementing a proper instrumental variable strategy, we are able to identify the contribution of workers diversity in cultural background, skills and demographic characteristics to valuable firm's innovation activity. The latter is measured by: (1) the firm's propensity to apply for a patent, (2) the number of patent applications (intensive margin) and (3) the firm's ability to patent in different technological areas (extensive margin). We find that skill and ethnic diversity plays an important role in propelling firm's innovation outcomes. Conversely, the effect of demographic diversity typically vanishes once detailed firm-specific characteristics are included as control variables.
\end{abstract}

JEL Classification: C23, J24, L20.

Keywords: Labor diversity, patenting activity, extensive and intensive margins.

*We thank Guglielmo Barone, Tor Eriksson, Michael Rosholm, and Måns Soderbom (alphabetical order) for helpful suggestions. In addition, we appreciate comments from participants at seminars organized by the Copenhagen Business School, University of Bergamo, Aarhus School of Business, University of Lausanne, and from participants at the following conferences: ESPE 2010, The 5th Nordic Summer Institute in Labor Economics, The 2010 Ratio Young Scientist Colloquium, ESEM 2010, CAED/COST 2010 in London and the 2010 International Symposium on Contemporary Labor Economics at WISE, Xiamen. Mariola Pytlikova gratefully acknowledges funding from the NORFACE Migration Programme "Migration: Integration, Impact and Interaction". The usual disclaimer applies.

${ }^{\dagger}$ Aarhus School of Business and Social Sciences, Aarhus University.

$\ddagger^{\ddagger}$ Aarhus School of Business and Social Sciences, Aarhus University.

$\S$ Corresponding author. Aarhus School of Business and Social Sciences, Aarhus University. Department of Economics, Hermodsvej 22, DK, 8230 Aabyhoj, Denmark. E-mail: marp@asb.dk 


\section{Introduction}

Many developed and developing countries have experienced several changes in the workforce composition which has lead to an increased heterogeneity of the labor force in terms of age, gender, skills and ethnicity. This is partly the result of policies adopted to counteract the problem of population aging, antidiscrimination measures, immigration and the worldwide globalization process (Pedersen, Pytlikova and Smith, 2008). From the demand side, we observe increasing diversity across many workplaces and we often hear about the importance of further internationalization and demographic diversification. The promotion of diversity is often perceived as a chance to improve learning and knowledge management capabilities and then enhance firm productivity (Parrotta, Pozzoli and Pytlikova, 2010). Besides, workforce diversity is believed to be an important source of innovation. For instance, in a relatively recent survey conducted by the European Commission, a large number of respondents identified innovation as a key benefit of having diversity policies and practices (European Commission, 2005). If this is the case, firms could benefit from the growing diverse cultural backgrounds, demographic, and knowledge bases of the workforces. Moreover, since there is a widespread consensus that innovation is crucial for sustainable growth and economic development (the new growth theory), knowing the link between workforce diversity and innovation seems to be essential for policy makers.

There are numerous, predominantly management studies focusing on the relationship between labor diversity and firm's innovation. In the literature a paradox has been recognized: whereas labor diversity can be a source of creativity and therefore foster innovation activity, a high degree of heterogeneity among workers may induce misunderstanding, conflicts and uncooperative behaviors within workplaces and in this way hinder innovation (Basset-Jones, 
2005). There is no general agreement on which effect may prevail. However, the paradox weakens if we distinguish between cognitive and demographic diversity. Specifically, differences in skills, education and more broadly in knowledge among employees seem to be beneficial rather than detrimental (Hong and Page, 2001 and 2004; Lazear, 1999). According to Lazear (1999), positive effects may prevail as long as workers' information sets are not overlapping but relevant to one another. Ambiguity instead persists for diversity in ethnic and demographic characteristics of employees. On the one hand, people of different cultural backgrounds, age and gender may provide diverse perspectives, valuable ideas, problem-solving abilities, and in this way facilitate the achievement of optimal creative solutions and therefore stimulate innovations (Watson, Kumar and Michaelsen, 1993; Drach-Zahavy and Somech, 2001; Hong and Page, 2001 and 2004). People of different ethnic backgrounds may also possess knowledge about global markets and customers tastes (Osborne, 2000; Berliant and Fujita, 2008) and different ways of searching for solutions to problems, i.e. heuristics, and therefore they are more likely to come up with innovative solutions than ethnically homogenous teams of workers (Hong and Page, 2004). On the other hand, such heterogeneities might create communication barriers, reduce the workforce cohesion and prevent cooperative participation in research activities, bringing high costs of "cross-cultural dealing" (Williams and O'Reilly, 1998; Zajac, Golden and Shortell, 1991; Lazear, 1999). Thus, it is still unclear whether more ethnically and demographically heterogeneous firms outperform the relatively more homogeneous ones with respect to innovation.

The empirical literature exploring the relationship between labor diversity and firm's innovation consists mainly of business case studies that often look at work-team compositions (Horwitz and Horwitz, 2007; and Harrison and Klein, 2007) or even focus on diversity in top management teams only (Bantel and 
Jackson, 1989; Knight, Pearce, Smith, Olian, Sims, Smith and Flood, 1999; Pitcher and Smith, 2001) ${ }^{1}$. That may be imputed to differences in research aims and approaches, but also to the lack of more comprehensive employeremployee data, which provide a notable amount of information on the labor force composition at the firm level. To the best of our knowledge, the evidence using more comprehensive data is virtually non-existent ${ }^{2}$.

In this paper, we investigate the nexus between labor diversity and innovation using a rich register-based linked employer-employee dataset (LEED) from Denmark for the years 1995-2003. Regarding measures of innovation, we follow previous literature and make use of information on patents to proxy for innovation (Griliches, 1990; Bloom and Van Reenen, 2002). Specifically, we use the following three measures: (1) firm's propensity to apply for a patent, (2) the number of patents introduced each year and (3) technological areas in which the firm has realized them. We investigate the effect of labor diversity on firm innovation by looking at three dimensions of employee diversity: cultural background, skills/education and demographics. Further, we deal with several problems that previous literature studying the impact of workforce diversity on innovation did not address properly. Most importantly, it might be that firms are aware of the importance of labor diversity and leverage it to improve

\footnotetext{
${ }^{1}$ There exists also some literature on the effects of diversity - typically ethnic labor diversity - on innovation using aggregate regional or industry data, for instance Kelley and Helper (1999), Feldman and Audretsch (1999), Anderson, Quigley and Wilhelmsson (2005), Niebuhr (2010); Kerr and Lincoln (2010).

${ }^{2}$ Since we began working on the paper, we became aware of two recent studies using more comprehensive data to analyze labor composition and innovation. The first work by Østergaard, Timmermarns and Kristinsson (2009) analyzes a cross-section of 1648 firms in Denmark to evaluate the effect of diversity in gender, age, ethnicity and education on firm's propensity to innovate. They find evidence of (a) positive effects of diversity in education and gender, (b) no significant effects of ethnic diversity and (c) negative effects of age diversity on firm's innovation. The second study by Söllner (2010) examines how occupational diversity, considered as a proxy of human capital heterogeneity, affects the firm's likelihood to introduce a product innovation. Controlling for age and tenure diversity among other covariates, he finds that "occupational diversity is positively related to the propensity to innovate". However, both studies present some limitations, among others they neglect the problem of possible endogeneity of the relationship between diversity and innovation, which we properly address in the present article.
} 
their performances; then the relationship under investigation may be affected by simultaneity or endogeneity. To address these concerns, we implement an instrumental variable (IV) strategy based on levels of workforce diversity computed for each commuting area, where a firm is located, as an instrument for the firm labor diversity. Further, as broadly documented by industrial and knowledge economics literature, firms are characterized by a different propensity to innovate. Thus, there exist unobserved and observed firm-specific heterogeneity that should be taken into account to evaluate the effect of any labor diversity dimension on firm's innovation outcome. Following Blundell, Griffith and Van Reenen (1995), we account for past firms' success in innovation and use pre-sample information as an observable proxy for unobservable permanent firm characteristics. Finally, we control for the potential role of the external knowledge in favoring firms' patenting activity and compute knowledge spillovers indicators based on geographical and technological distances between firms.

Implementing alternative estimation techniques, we find an evidence of the key role of the skill diversity in promoting firm's innovation as measured by the probability to innovate, the number of patent applications and patent grants. Diversity in cultural background has a positive and significant influence, too. Effects of diversity in demographics turn to be mostly insignificant when shares of male and differently aged employees are included as controls. Our results show that firms with more diverse workforce in terms of skills/education are more likely to patent in more than one technological field. Finally, we find that the beneficial effect of skill and ethnic diversity on innovation materializes for the white-collar occupations only, and not for the blue-collar occupations. These results support the hypothesis that diverse workers tend to have a wider pool of different experiences, knowledge bases and heuristics boosting their problemsolving capacities and creativity, which in turn facilitate innovations. In this 
regard, our findings are consistent with the theoretical frameworks proposed by Hong and Page (2001 and 2004) and Berliant and Fujita (2008). Hence, our results suggest firms to focus on recruitment strategies that explicitly account for heterogeneity in skills and ethnicity. This article may also provide some suggestions to public authorities in terms of innovation policies. Given that innovation is considered as one of the most important components for the long-term economic growth (new growth theory), hence investigating the determinants of the innovation process may also lead to the identification of the sources of a sustainable growth. In this regard, public institutions and policy makers could invest resources to promote skill and ethnic diversity within workplaces and in such a way increase the innovation, and ultimately the economic growth.

The structure of the paper is as follows: section 2 briefly describes the data, section 3 provides details on the empirical strategy, sections 4 and 5 explain all the results of our empirical analyses and section 6 offers some concluding remarks.

\section{Data}

\subsection{Data sources}

The data set we use for our analysis is obtained by merging three different data sources from Denmark. The first one is the 'Integrated Database for Labor Market Research' (IDA), which is a register-based LEED managed by Statistics Denmark, a Danish governmental institute responsible for creating statistics on the Danish society and economy. IDA contains a broad set of information on individuals and firms for years 1980-2006. In particular, we are interested in gender, age, nationality, education, occupation and place of work, but also whether a firm is (partially or totally) foreign-owned and a multi-establishment. 
The second data source is a register of firms' business accounts (REGNSKAB) that provides information on a number of financial items, which we need in order to construct values of firms' capital stock, information on whether a firm is an exporter and the 3-digit industry, in which the firm operates. This database is also maintained by the Statistics Denmark and reports data for the period 1995$2006 .{ }^{3}$ In REGNSKAB it is possible to identify partially and totally imputed values, which we exclude from our final data set in order to avoid any bias in the estimates. The last data source is a collection of patent applications sent to the European Patent Office (EPO) by Danish firms. ${ }^{4}$ It covers a period of 26 years (1978-2003) and allows us to account for 2822 applicants and 2244 granted firms. ${ }^{5}$ We disregard those industries where there were no patenting firms during the period covered in our empirical analysis. ${ }^{6}$ We also exclude enterprises with less than 10 employees from our sample to allow all investigated firms potentially to reach the highest degree of (ethnic) diversity at least when an aggregated specification is used. Thus, our final data set contains information on approximately 14,000 firms per year over a period of 9 years (1995-2003).

\subsection{Diversity measures}

The workforce diversity (heterogeneity) measures used in this article are

\footnotetext{
${ }^{3}$ Part of the statistics in REGNSKAB refers to selected firms for direct surveying: all firms with more than 50 employees or profits higher than a given threshold. The rest is recorded in accordance with a stratified sample strategy. The surveyed firms can choose whether to submit their annual accounts and other specifications or to fill out a questionnaire. In order to facilitate responding, questions are formulated in the same way as required in the Danish annual accounts legislation.

${ }^{4}$ The access to these data has been made possible thanks to the Center for Economic and Business Research (CEBR), an independent research center affiliated with the Copenhagen Business School (CBS).

${ }^{5}$ More details concerning the construction and composition of the data set can be found in Kaiser, Kongsted and Rønde (2008).

Specifically, we drop the following industries: agriculture, fishing and quarrying; electricity, gas and water supply; sale and repair of motor vehicles; hotels and restaurants; transports; and public services.
} 
computed at the firm level and based on the Herfindahl index. The latter combines two important dimensions of diversity: the "richness", which refers to the number of defined categories within a firm, and the "evenness", which informs on how equally populated such categories are. Specifically, our diversity measures represent weighted averages of Herfindahl indexes computed at the workplace level:

$$
D i v_{-} h_{i t}=\sum_{w=1}^{W} \frac{N_{w}}{N_{i}}\left(1-\sum_{s=1}^{S} p_{w s t}^{2}\right)
$$

where Div $h_{i t}$ is the diversity index of firm $i$ at time $t$ for the dimension $h, W$ is the total number of workplaces ( $w$ refers to a given workplace) constituting the firm, and therefore $N_{w}$ and $N_{i}$ denote the total number of workers at the workplace and firm levels, respectively. Thus, the ratio between the last two variables corresponds to the weighting function, while $p_{w s t}$ is the proportion of the workplace's employees falling into each category $s$ at time $t$, with $s=$ $1,2, \ldots, S$. The diversity index has a minimum value, which takes value on zero if there is only one category represented within the workplace, and a maximum value equal to $\left(1-\frac{1}{S}\right)$ if all categories are equally represented. The index can be interpreted as the probability that two randomly drawn individuals in a workplace belong to different groups.

As we distinguish between cultural, educational (skill) and demographic diversity, a separate measure is computed along each of the three cited dimensions. Diversity in cultural background is associated with employees' country of origin ${ }^{7}$ and is built by using the following eight categories: North America and Oceania, Central and South America, Africa, Western and Southern Europe, Formerly Communist Countries, East Asia, Other Asia, Muslim Countries. ${ }^{8}$ Diversity in education is based on six categories. In particular, tertiary education $(\mathrm{PhD}$, Master and Bachelor) is divided into the following four groups: engineering,

\footnotetext{
${ }^{7}$ Native Danes and the second generation of immigrants are excluded.

${ }^{8}$ See Appendix1 for more details about the countries belonging to each ethnic category.
} 
humanities, natural sciences and social sciences. The other two categories are represented by secondary and compulsory education. Eight categories instead refer to the demographic diversity, which is computed by combining gender and four age dichotomous indicators associated with quartiles of the overall age distribution.

However, given that the overall categorization might be somehow arbitrary, we decide to use a more disaggregated one, too. The alternative cultural background diversity is based on linguistic classification. ${ }^{9}$ Specifically, we group foreign employees together by family of languages, to which the language spoken in their home country belongs. Using the third linguistic tree level language classification drawn from Ethnologue, we end up having 40 linguistic groups. ${ }^{10}$ Further, our disaggregated diversity indexes in education and demographics are based on eight and ten categories, respectively. Differently from the former classification, the secondary education is split into 3 sub-groups: high school, business high school and vocational education. Demographic diversity is computed by combining gender and five age dichotomous indicators associated with quintiles of the overall age distribution.

\subsection{Descriptive statistics}

Table 1 reports some descriptive statistics (median, mean and standard deviation) of the variables used in our empirical analysis. The firm population is divided into two groups based on whether a firm applied for at least one patent (patenting firm) or did not. Patenting firms are characterized by notably

\footnotetext{
${ }^{9}$ Previous literature argues that linguistic distance serves as a good proxy for cultural distance (Guiso, Sapienza and Zingales, 2009; Adsera and Pytlikova, 2010).

${ }^{10}$ The linguistic classification is more detailed than the grouping by nationality. Specifically, we group countries (their major official language spoken by the majority in a particular country) by the third linguistic tree level, e.g. Germanic West vs. Germanic North vs. Romance languages. The information on languages is drawn from the encyclopedia of languages "Ethnologue: Languages of the World", see the Appendix section for more details about the list of countries and the linguistic groups included.
} 
higher values of capital and labor inputs: the average capital stock is almost 9.5 times the value of the non-patenting firms. The latter are more likely to be single-establishment companies and markedly less export-oriented: on average the share of exporters halves among those firms that have never applied for a patent. Small differences are shown instead for the foreign ownership status: the foreign capital penetration is quite low among Danish firms. For the purposes of our analysis it appears relevant to take into account the role of external sources of knowledge since they may facilitate firms' innovation activity. Although we already control (using the export dummy) whether firms compete in the international arena and then have access to foreign knowledge, more precise indexes of knowledge spillovers can be defined at the national level. Specifically, we construct two measures of knowledge spillovers, one based on the geographical distance and the other on the technological proximity, see Appendix 2 for a detailed description of the external knowledge indexes. Looking at these measures of knowledge spillovers, see Table 1, we find no evidence of diffused clustering behavior or huge differences in technological distance between the two groups of firms.

As evident from the Table 1, there are remarkable differences between patenting and non-patenting firms with respect to firms' workforce composition. Not surprisingly, patenting firms are characterized by larger shares of highly educated employees, white-collar workers and managers, whereas the opposite holds true for middle managers. Interestingly, patenting firms also record a higher share of female and foreign employees. Workers in these knowledge-based firms are slightly older on average terms: presumably the share of young employees is lower because patenting firms hire a wider proportion of well trained and experienced people. As a matter of fact long tenure profiles are more common within patenting firms' environment. Diversity indexes register higher values 
for patenting firms. Particularly evident is the differential in the ethnic heterogeneity that is 3.5 times larger on average with respect to non-patenting firms. These indexes also report substantial lower skill diversity, which is $16 \%$ poorer in mean values. Thus, the presented descriptives raise a reasonable interest in evaluating the "nexus" between firms' patenting behavior and diversity in ethnicity, education and demographics.

\section{Econometric methods}

\subsection{Propensity to innovate}

To investigate the effect of labor diversity on firm's propensity to innovate, we employ a standard binomial regression technique in our analyses. Specifically, we estimate the following probit model:

$$
\begin{gathered}
\left\{\begin{array}{l}
z_{i t}=1 \quad \text { if } z_{i t}^{*}>0 \\
z_{i t}=0 \text { otherwise }
\end{array}\right. \\
\text { with } z_{i t}^{*}=\gamma_{c} \text { Div_c } c_{i t}+\gamma_{s} D_{i v} s_{i t}+\gamma_{d} \text { Div_d } d_{i t}+x_{i t}^{\prime} \beta+\eta_{i}+v_{i t}
\end{gathered}
$$

where $z_{i t}^{*}$ denotes the unobservable variable inducing firm $i$ to apply at least once for a patent at time $t ; z_{i t}$ indicates whether firm $i$ concretely has applied at time $t$; the first three terms at the right-hand side are diversity in cultural background, skills and demographics respectively. The vector $x_{i t}^{\prime}$ includes an extensive set of observable characteristics, like, among others, the external knowledge indexes and the firm-specific characteristics described in section $2.3 ; \eta_{i}$ denotes the firm-specific unobservable effect and $v_{i t}$ is the error term. Similar to Blundell, Griffith and Van Reenen (2002), we proxy for the unobserved heterogeneity 
$\eta_{i}$ by arguing that the main source of unobserved permanent differences in firms' capabilities to innovate can be captured by the pre-sample history of innovative successes. In line with that, we assume that the firms' average number of patent applications provides a good approximation of the above unobservable heterogeneity component $\eta_{i}$. However, an overall increase in the number of patent applications is recorded during the pre-sample period. Thus, as in Kaiser, Kongsted and Rønde (2008) we deal with that by normalizing a firm's number of patents in a pre- sample year by the total number of patents applied for during that year:

$$
\eta_{i}=\frac{1}{T} \sum_{t=\tau}^{T+\tau}\left(\frac{y_{i t}}{\sum_{i=1}^{I} y_{i t}}\right)
$$

As firms can leverage labor diversity to improve their innovation performances, we also instrument our variables of interest in order to obtain a causal effect of workforce diversity on firm innovation activities. Specifically, we implement an instrumental variable (IV) strategy based on the levels of workforce diversity in cultural background, skills and demographic characteristics computed at the commuting area ${ }^{11}$ where the firm is located. ${ }^{12}$ The so-called functional economic regions or commuting areas are identified using a specific algorithm based on the following two criteria. Firstly, a group of municipalities constitute a commuting area if the interaction within the group of municipalities is high compared to the interaction with other areas. Furthermore, at least one municipality in the area must be a center, i.e. a certain share of the employees living in the municipality must work in the municipality, too (Andersen, 2000).

\footnotetext{
${ }^{11}$ The commuting area level diversity is calculated by averaging the firm level diversity of all firms belonging to a specific commuting area.

${ }^{12}$ Unfortunately in our data set it is not possible to observe in which area each establishment of a multi-establishment firm is located. For the multi-establishments firms, the information about the location is only provided for the headquarter. However, we do not think this represents a serious problem as multi-establishments firms constitute only $26 \%$ of our sample. This is reinforced by the fact that we always reject the hypothesis that our instrument is weak.
} 
In total there are 51 commuting areas identified, see Figure 1.

We believe that diversity at the commuting area level presents a suitable supply driven instrument for workplace level diversity because commuting areas in Denmark (except for the area around Copenhagen) are typically relatively small and therefore firms very likely recruit workers from a given local supply of labor, which is characterized by a certain degree of heterogeneity. This argument is further reinforced by the role of networks in the employment process (Montgomery, 1991, Munshi, 2003). Thus firms placed in areas with a high labor diversity are also more likely to employ more a diverse workforce. Moreover, the rather low residential mobility in Denmark (Deding, Filges and Van Ommeren, 2009) seems to support the properness of our IV strategy. ${ }^{13}$ To reinforce the exogeneity of our instruments we exclude each firm workforce from the computation of labor diversity at the related commuting area. We use the same IV strategy for the analyses of intensive and extensive margins.

\subsection{Intensive margins}

As the number of patents is by definition restricted to non-negative integers, the econometric strategy used to analyze the relationship between intensive margins of patenting activity and labor diversity is grounded on the family of count models. As a starting point we assume that the data generating process follows a Poisson distribution. If the random variable $Y_{i t}$, in our case number of patent applications filed by firm $i$ at time $t$, is Poisson distributed, then the probability that exactly $y$ applications are observed is as follows

\footnotetext{
${ }^{13}$ Furthermore, one may point towards potentially endogenous location behavior of immigrants. The validity of our instrument may be strengthened by the spatial dispersion policy implemented for immigrants between 1986 and 1998 by the Danish authorities. The dispersal policy implied that new refugees were randomly distributed across locations in Denmark, see e.g. Damm (2009).
} 


$$
P\left(Y_{i t}=y \mid \lambda_{i t}\right)=\frac{e^{-\lambda_{i t}} \lambda^{y}}{y !} .
$$

Covariates can be introduced by specifying the individual mean as

$$
\lambda_{i t}=\exp \left(\beta_{c} D i v_{-} c_{i t}+\beta_{s} D i v_{-} s_{i t}+\beta_{d} D i v_{-} d_{i t}+w_{i t}^{\prime} \beta_{w}+\eta_{i}\right),
$$

where $\eta_{i}$ stands for the unobserved time-invariant firm-specific heterogeneity term and $w_{i t}$ is a vector of patent production determinants, as specified in subsection 3.1. Following Blundell, Griffith and Van Reenen (1995), we also include, among the covariates $w_{i t}$, the discounted patent stock of firm $i$ at period $t-1$ in order to account for potential state dependence in patenting activity. This is calculated as

$$
\text { disc_stock } k_{i t-1}=y_{i t-1}+(1-\delta) d_{i s c \_s t o c k_{i t-2}},
$$

where $y_{i t-1}$ is the lagged number of patent applications and $\delta$ is the depreciation rate set equal to 30 per cent as in Blundell, Griffith and Van Reenen (1995).

We also add a dummy variable taking value on zero if the firm had never innovated prior to 1995, to capture persistent differences between patenting and non-patenting firms (Blundell, Griffith and Van Reenen, 1995; Blundell, Griffith and Van Reenen, 1999). In addition, this dummy variable represents a remedy for the so-called "zero-inflation problem" given that in our data many firms never applied for a single patent. The pre-sample information technique is feasible in a study like ours because we have a long series for the dependent variable (1977-1994) prior to the starting period (1995) of the final sample in 
use.

However, as the Poisson model imposes the equality of conditional mean and conditional variance of the dependent variable distribution, we also decide to implement a negative binomial model, which is more flexible. In fact, it allows the variance to exceed the mean and the dispersion parameter $\alpha$ to vary randomly between firms ${ }^{14}$ :

$$
P\left(Y_{i t}=y \mid \alpha_{i}, \lambda_{i t}\right)=\frac{\Gamma\left(y+\alpha^{-1}\right)}{y ! \Gamma\left(\alpha^{-1}\right)}\left(\frac{\alpha^{-1}}{\alpha^{-1}+\lambda_{i t}}\right)^{\alpha^{-1}}\left(\frac{\lambda_{i t}}{\alpha^{-1}+\lambda_{i t}}\right)^{y}
$$

where $\Gamma$ is the Gamma distribution.

As we have mentioned before, one may argue that the relationship between firm-patenting activity and diversity could be affected by endogeneity. The latter issue might arise because there could be unobserved firm-specific factors influencing both the number of patent applications and the degree of labor diversity. To address these concerns, we apply a two-stage IV procedure to the Poisson model as suggested by Vuong (1984). In this case, equation (1) is specified as follows:

$$
\lambda_{i t}=\exp \left(\beta_{c} D i v_{-} c_{i t}+\beta_{s} D i v_{-} s_{i t}+\beta_{d} D i v_{-} d_{i t}+w_{i t}^{\prime} \beta_{w}+\eta_{i}+u_{i t}\right)
$$

where the term $u_{i t}$ can be interpreted as unobserved heterogeneity correlated with the diversity indexes but uncorrelated with the vector of patent production determinants $w_{i t}{ }^{15}$ To model the correlation between the endogenous variables and $u_{i t}$, we specify a system of linear reduced-form equations, one for each diversity index. This is

\footnotetext{
${ }^{14}$ The Negative binomial model coincides to a Poisson distribution when $\alpha=0$.

${ }^{15}$ The error term $u_{i t}$ is added to allow for endogeneity. It also induces overdispersion, so that the Poisson model and the Negative binomial model are empirically equivalent.
} 


$$
\left\{\begin{array}{l}
\text { Div_c } c_{i t}=w_{i t}^{\prime} \gamma_{w}+z_{i t}^{\prime} \gamma_{z}+\varepsilon_{c i t} \\
D i v_{-} s_{i t}=w_{i t} \gamma_{w}+z_{i t}^{\prime} \gamma_{z}+\varepsilon_{s i t} \\
D i v_{-} d_{i t}=w_{i t}^{\prime} \gamma_{w}+z_{i t}^{\prime} \gamma_{z}+\varepsilon_{d i t}
\end{array}\right.
$$

where $z_{i t}$ is the vector of exogenous variables that affects firm level diversity, but does not directly affect the number of patent applications. As in section 3.1 , the excluded variables are the diversity indexes computed at the commuting area where the firm is located and the model is just-identified. The error terms $\varepsilon$ are assumed to have zero mean and to be correlated across equations for a given firm $i$, but uncorrelated across observations. Furthermore, we assume that the errors $u$ and $\varepsilon$ are related via

$$
u_{i t}=\rho_{c} \varepsilon_{c i t}+\rho_{s} \varepsilon_{s i t}+\rho_{d} \varepsilon_{d i t}+\zeta_{i t}
$$

where $\zeta_{i t} \sim\left[0, \sigma_{\zeta}^{2}\right]$ is independent of $\varepsilon_{c i t}, \varepsilon_{s i t}$ and $\varepsilon_{c i t}{ }^{16}$ Substituting equation (3) in equation (2) for $u_{i t}$ and taking the expectation with respect to $\zeta$ yields

$$
E_{\zeta}(\lambda)=\exp \left(\beta_{c} D i v{ }_{-} c+\beta_{s} D i v_{-} s+\beta_{d} D i v_{-} d+w^{\prime} \beta+\eta+\ln E\left(e^{\zeta}\right)+\rho_{c} \varepsilon_{c}+\rho_{s} \varepsilon_{s}+\rho_{d} \varepsilon_{d}\right) .
$$

The constant term $\ln E\left(e^{\zeta}\right)$ can be absorbed in the coefficient of the intercept as an element of $w$. It follows that

$$
\lambda_{i t}=\exp \left(\beta_{c} D i v_{-} c_{i t}+\beta_{s} D i v_{-} s_{i t}+\beta_{d} D i v \_d_{i t}+w_{i t}^{\prime} \beta_{w}+\eta_{i}+\rho_{c} \varepsilon_{c i t}+\rho_{s} \varepsilon_{s i t}+\rho_{d} \varepsilon_{d i t}\right),
$$

where $\varepsilon_{c i t}, \varepsilon_{s i t}$ and $\varepsilon_{c i t}$ are the new additional variables. Given that the former variables are unobservable, we follow a two-step estimation procedure where we first estimate and generate them and second we estimate parameters of the Poisson model after replacing $\varepsilon_{c i t}, \varepsilon_{s i t}$ and $\varepsilon_{c i t}$ with $\hat{\varepsilon}_{c i t}, \hat{\varepsilon}_{s i t}$ and $\hat{\varepsilon}_{c i t}$. Obviously, the variance and covariance matrix of the two-step estimator needs

\footnotetext{
${ }^{16}$ This assumption means that $\varepsilon$ is a common latent factor that affects both diversity and patent applications and is the only source of dependence between them, after controlling for the influence of the observable variables.
} 
to be adjusted for the above replacement by bootstrapping the sequential twostep estimator.

\subsection{Extensive margins}

The estimation approach used to evaluate the extensive margins of firms' patenting behavior is similar to the one adopted for the firms' propensity to patent. Although the count data models would be more suitable for the analyses of relationship between workforce diversity and the number of different technological areas of patent application, our data and concretely the lack of minimum observations required to run count data models do not allow us to use them. Instead, we evaluate whether more labor diversity increases the probability of a firm to (apply for a) patent in more than one technological area.

\section{Results}

This section reports findings for each of the outcome dimensions we look at: propensity to innovate, intensive and extensive margins. Several specifications among the different econometric models here employed help in understanding the strength of our results. Further, in the sensitivity analyses subsection we examine whether the results differ between white- and blue-collar occupations, and across alternative diversity and innovation measures.

\subsection{Results on labor diversity and propensity to innovate}

Table 2 reports estimates concerning the propensity to patent. As explained in the previous section, we implement probit models having as dependent variable the dummy indicating whether a firm has applied for a patent in a given 
year. In column 1 we show a model with the three workforce diversity indexes as the only regressors. The workforce diversity can explain about $15 \%$ of the overall variation in the dependent variable and is associated with sizable and significantly positive effects. Augmenting the specification by including industrial, time and size dummies reduces the size of our coefficients of interest and almost doubles the explanatory power of the model. Columns 3 and 4 show results from probit models with all other covariates; while the former treats the diversity indexes as exogenous variables, the latter shows the IV specification with workforce diversity levels at commuting areas as instruments for the firm workforce diversity. Results between the two full specification models are rather similar and imply that a standard deviation change in the ethnic and skill diversity increases the probability to apply for patent by 0.020 and 0.044 percent, respectively.

Turning to the other control variables, the inclusion of pre-sample fixed effects turns out to be important to deal with time invariant unobserved heterogeneity among firms. The variable attaches statistically significant positive coefficient and it also corrects the estimates on labor diversity. Further, firms with higher shares of highly skilled and vocational workers, and exporting firms have higher propensity to patent. Instead, the knowledge spillovers based on technological and geographical distances, and the average firm tenure do not explain much of such a propensity.

As explained above, we run additionally the models using diversity indexes based on more detailed category specification; the results are shown in the Table 2, columns 5 to 8 . Now the effect of a standard deviation change in the skill diversity produces an increase in the probability to apply for a patent by 0.059 percent, whereas the positive effect of ethnic diversity appears negligible. 


\subsection{Results on labor diversity and intensive margins}

In the next step, we analyze how firm workforce diversity contribute to the number of patent application. Tables 3 and 4 show the results of the intensive margins analyses using the aggregate specification of diversity in cultural background based on nationality and using the disaggregated specification based on linguistic grouping classification, respectively. The estimated coefficients represent elasticities. The first column in Table 3 shows the output of a Poisson regression having only the diversity measures as regressors: the coefficients to all diversity indexes are large, positive and significant. Once more, after including the industry, time and size dummies (column 2) and especially in the full model specification (column 3) their dimension and statistical significance decreases. Nonetheless, except for the demographic heterogeneity, the diversity indexes retain their statistically significant positive coefficients; also if we apply the instrumental estimation strategy (column 4). Taking the last IV Poisson specification as the most reliable, we find that one percent increase in the skill diversity leads to 1.7 percentage increase in the number of patent applications. This effect is quite sizable given that the elasticity associated to a production input like human capital (proxied by the share of highly skilled workers) is just about 1.6 times larger. Important effects are also related to the shares of technicians, capital and labor stock, while knowledge spillovers variables do not show significant contributions to the overall number of patent applications. As in the case of patenting propensity, exporters benefit from the knowledge gained in the international markets. The results obtained by implementing the more flexible negative binomial models are, except for the effect of ethnic diversity, very similar to the results from the Poisson models, see Table 3 , columns 5 to 7.

Table 4 reports results for the disaggregated classification of labor diversity 
dimensions. Although the results are very similar to the results using aggregate diversity specification shown in Table 3 , there are some changes worth noting. Specifically, in the IV Poisson (column 4) the coefficient on the ethnic diversity turns to be insignificant; in addition a larger effect is associated with heterogeneity in skills. According to this specification a one percent increase in the educational heterogeneity implies a 2.23 percent increase in the number of patent applications. ${ }^{17}$

\subsection{Results on labor diversity and extensive margins}

Table 5 reports the effects of labor diversity on the probability of applying for a patent in different technological areas in a given year. The structure of this table is similar to Table 2. The low number of annual patent applications in each technological area does not allow us to use potentially more suited count models. Regarding the variables of interest, we find that the diversity indexes alone explain 6.8 percent of the overall variation in the dependent variable, coefficients to all diversity indexes are positive and statistically significant. However, the significance of the diversity in cultural background and demographics vanishes when all covariates are included. Overall, we find that skill diversity is important for patenting in different technological areas. Taking the lowest estimate between the full IV specifications, it turns out that a standard deviation increase in skill diversity is associated to a raise of about 7.2 percent in the probability to patent in different technological fields. Thus it seems as the skill diversity is 17

We have also investigated whether the effects of a particular dimension of diversity can be influenced by other forms of labor heterogeneity by inclusion of all possible interaction couples between the diversity indexes. Furthermore, driven by the hypothesis that there might be complementarities among different skills and demographic groups, in particular young and educated workers together with a more diverse workforce can stimulate innovation and creativity, we have augmented our models with interactions between diversity indexes and shares of highly skilled and younger workers. Nevertheless, none of the interactions turned out to be statistically significant. Figures showing marginal effects of the interactions are available from the authors upon request. 
much more relevant for patenting in different technological areas than for the patenting per se.

\section{Sensitivity analysis}

In the next section, we examine whether the effects of labor diversity on patenting activity of firms differ between different occupational categories of workers, and across alternative diversity and innovation measures.

Firstly, we calculate our diversity indexes for white- and blue-collar occupations and include both of them in the same regression. This is driven by the idea that diversity could play a different role for distinct occupational groups and consequently have diverse effects on firm innovation. In particular, we would expect that the beneficial effects of diverse problem-solving abilities and creativity would materialize more in terms of innovation for white-collar occupations compared to blue-collar occupations. On the other hand, the white-collar occupations are more likely to rely on sound communication between workers compared to blue-collar occupations. Thus, we would expect large positive effects of skill/educational diversity on innovation for white collar occupations, whereas the effects of demographic and cultural diversity can be ambiguous depending on which effect prevails: the positive effect from better decision making, problem-solving abilities and creativity, or negative effect caused by the communication costs and costs of "cross-cultural dealing". The results of the effect of diversity indexes calculated separately for the two occupational groups on firm probability to innovate and number of patent applications are presented in Table 6 (columns 1 and 2) and Table 7 (columns 1 and 2), respectively. Indeed, we find that workforce diversity is much more important for white-collar than for blue-collar occupations. The effect of skill and ethnic diversity among the white-collar workers on probability to innovate and the number of patents is 
positive and statistically significant. On contrary, the effect of demographic diversity is insignificant for both white- and blue-collar occupations. In the model using detailed/disaggregated diversity indexes, the effect of demographic diversity on the number of patent applications turns out to be negative, see Table 7. This is partly consistent with the notion by Lazear (1999). Finally, it is also worth noting that the positive effect of ethnic and skill diversity is larger for the number of patent application than for the probability to innovate.

Further, as a part of the sensitivity analysis we evaluate eventual variations in the effects of labor diversity when the diversity measure is differently computed. In particular, we use two alternative diversity indexes: the ShannonWeaver entropy and the richness indexes. The former is considered as one of the most profound and useful diversity indexes in biology (Maignan, Ottaviano, Pinelli and Rullani, 2003), whereas the latter is defined as a number of categories observed for each dimension of interest (it does not account for the "evenness" dimension). Final checks come from the evaluation of the relationship between labor diversity and firms' granted patents rather than from patent applications. The reason behind this sensitivity is based on the potential critique that applications may not result in granted patents ${ }^{18}$. Table 6 reports marginal effects of the three dimensions of labor diversity on the firm probability to innovate. These findings do not substantially differ from the main results. Interestingly, the role of skill heterogeneity strengthens when the outcome variable is based on patent grants rather than applications. This result is also confirmed in analysis of the number of patents shown in Table 7. Overall, the results of sensitivity analysis are in line with the main findings and hence their overall interpretation

\footnotetext{
${ }^{18}$ Unfortunately, given the relatively low number of patenting firms (and the delay occurring between the application year and period in which the potential grant is received), it is not possible to evaluate how our main findings might have changed for the probability to patent in different technological areas in a given year. The results with the alternative diversity indexes, Shannon-Weaver entropy and the richness indexes, are available from the authors upon request.
} 
does not vary. That notably corroborates our main analyses and provides an evident support to the conclusions, which are summarized in the next section.

\section{Discussion and conclusions}

In this paper we provide an overall assessment of the nexus between labor diversity and firms' patenting behavior. To the best of our knowledge, this study represents the first concrete attempt to formalize and generalize the relationship of labor diversity and innovation by using detailed information on firms' workforce composition.

Specifically, controlling for a large number of firm-specific characteristics, proxying for time-invariant unobservables, including reasonable measures of knowledge spillovers, adopting alternative categorizations for diversity and using proper instruments for the labor diversity dimensions of interest, we find robust evidence that diversity in education and skills of the labor force is a fundamental source of innovation. That facilitates firms' patenting activity in several ways: (a) slightly increases their propensity to (apply for a) patent, (b) increases the overall number of patent applications and (c) enlarges the breadth of patenting technological fields. Being prudent in the quantification of skill heterogeneity effects on all these aspects of patenting activities, we find that a percentage change in skill diversity increases the number of firms' patent applications by 1.7 percent. The contribution of skill diversity in terms of general propensity to send at least one patent application in a given year is quite modest: a standard deviation change in its value turns to raise such a probability by 0.044 percent. However, the effect of educational diversity on extensive margins is large, a standard deviation change in skill diversity leads to a raise of about 7.2 percent in the firms' probability to apply for a patent in different technological areas. Thus, in order to widen the patent technological spectrum it seems to 
be fundamental to increase the heterogeneity in the workers' competencies and knowledge bases. Furthermore, we find a statistically significant positive effect of ethnically diverse workforce on the propensity to innovate and on the number of patent applications. The valuable influence of ethnic diversity, albeit smaller in its magnitude than the effect coming from skill/educational labor diversity, is not negligible. Regarding the results of demographic diversity on innovation, its effect typically vanishes once detailed firm-specific characteristics are included as control variables. Finally, we find that the beneficial effect of skill and ethnic diversity on innovation materializes for the white-collar occupations only, and not for the blue-collar occupations. These results support the hypothesis that diverse workers tend to have a wider pool of different experiences, knowledge bases and heuristics boosting their problem-solving capacities and creativity, which in turn facilitate innovations. In this regard, our findings are consistent with the theoretical frameworks proposed by Hong and Page (2001 and 2004) and Berliant and Fujita (2008).

The overall picture coming out from our empirical analysis seems to be particularly relevant not only for the design of firms' innovation strategies but also for public policies aimed at fostering innovation. Our results give an important insight into the technological process, a driver of productivity growth and ultimately an economic growth. We find that an increase in firm labor diversity in terms of education and ethnicity has a positive effect on the firm innovation process. Thus, governmental policies aimed to encourage the employment of workers with different educational and cultural backgrounds can be beneficial in terms of improvements in firms' patenting activities, increasing both private returns, directly, and social gains, through knowledge diffusion mechanisms. Nowadays, such policies might contribute to attract foreign and domestically less abundant skilled labor by supporting investments in human capital. That 
could be one of the determinants to invert the general decline in patenting activity recorded during the recent economic crisis among the OECD countries (OECD, 2009). 


\section{References}

[1] Adsera, A. and Pytlikova, M. "The Role of Language in Shaping International Migration: Evidence from OECD Countries 1985-2006," Unpublished manuscript, 2010.

[2] Andersen, A. K. "Commuting Areas in Denmark", AKF working paper (2000).

[3] Audretsch, D. B. and Feldman, M. P. "R\&D Spillovers and the Geography of Innovation and Production." American Economic Review, Vol. 86 (1996), pp. 630-640.

[4] Adams, J. D. "Fundamental Stocks of Knowledge and Productivity Growth", Journal of Political Economy, Vol. 98 (1990), pp. 673-703.

[5] ADAms, J.D. and JAFFe, A. "Bounding the Effects of R\&D: An Investigation Using Linked Establishment and Firm Data" Rand Journal of Economics, Vol. 98 (1996), pp. 673-702.

[6] Anderson R, Quigley J M, Wilhelmsson M. "Agglomeration and the spatial distribution of creativity", Papers in Regional Science, 83 (2005): pp. $445-464$.

[7] Bantel, K. A. and JACKson S. E. "Top Management and Innovations in Banking: Does the Composition of the Top Team Make a Difference?", Strategic Management Journal, Vol. 10 (1989), pp. 107-124.

[8] Basset-Jones, N. "The Paradox of Diversity Management, Creativity and Innovation", Creativity and Innovation Management, Vol. 14 (2005), pp. 169-175.

[9] Berliant M. and Fujita M. "Knowledge Creation as a Square Dance on the Hilbert Cube." International Economic Review, 49 (2008), pp. $1251-1295$.

[10] Bloom, N. and Van Reenen, J. "Patents, real options and firm performance", Economic Journal, Vol. 112 (2002), pp. 97-116.

[11] Blundell, R., Griffith R. and Van Reenen J. "Dynamic Count Data Models of Technological Innovation", Economic Journal, Vol. 105 (1995), pp. 333-44.

[12] Blundell, R., Griffith R. and Van Reenen J. "Market Share, Market Value and Innovation in a Panel of British Manufacturing Firms", The Review of Economic Studies, Vol. 66 (1999), pp. 529-554.

[13] Blundell, R., Griffith R. and Windmeijer F. "Individual Effects and Dynamics in Count Data Models", Journal of Econometrics, Vol. 108 (2002), pp. 113-131. 
[14] Cohen, W.M. and Levinthal D.A. "Absorptive Capacity: A New Perspective on Learning and Innovation", Administrative Science Quarterly, Vol. 5 (1990), pp. 128-152.

[15] Deding, M., Filges, T. and Van ommeren J. "Spatial Mobility and Commuting: the Case of Two-Earner Households", Journal of Regional Science, Vol. 49 (2009), pp. 113-147.

[16] Drach-ZAhavy A. and Somech A. "Understanding Team Innovation: The Role of Team Processes and Structures", Group Dynamics: Theory, Research, and Practice, Vol. 5 (2001), No. 2, pp. 111-123.

[17] European commission "The Business Case for Diversity: Good Practices in the Workplace" (2005).

[18] Feldman, M. P. and Audretsch, D. B. "Innovation in Cities: ScienceBased Diversity, Specialization and Localized Competition." European Economic Review, Vol. 43 (1999), pp. 409-429.

[19] GRILICHES, Z. "Patent Statistics as Economic Indicators: A Survey", Journal of Economic Literature, vol. 28 (1990), pp. 1661-1707.

[20] Guiso, L., Sapienza, P. and Zingales L. "Cultural Biases in Economic Exchange?," Quarterly Journal of Economics, Vol. 124 (2009), pp. 10951131.

[21] Harrison, D. A. and Klein K. J. "What's the difference? Diversity constructs as separation, variety, or disparity in organizations", Academy of Management Review, Vol. 32 (2007), pp. 1199-1228.

[22] Hong, L. and PAgE Scott E. "Problem Solving by Heterogeneous Agents" Journal of Economic Theory, Vol. 97 (2001), Issue 1, pp. 123-163.

[23] Hong, L. and Page Scott E. "Groups of Diverse Problem Solvers Can Outperform Groups of High-Ability Problem Solvers," Proceedings of the National Academy of Sciences, Vol. 101 (2004), No. 46, pp. 16385-16389.

[24] Horwitz S. K. and Horwitz I. B. "The Effects of Team Diversity on Team Outcomes: A Meta-Analytic Review of Team Demography", Journal of Management, Vol. 33 (2007), pp. 987-1015.

[25] JAFFE, A. B. "Technological Opportunity and Spillovers of R\&D", American Economic Review, Vol. 76 (1986), pp. 984-1001.

[26] Kaiser, U., Kongsted H. and Rønde T. "Labor Mobility and Patenting Activity", CAM working paper no. 16 (2008).

[27] KerR, W., Lincoln, W. "The Supply Side of Innovation: H-1B Visa Reforms and US Ethnic Invention", Journal of Labor Economics, Vol. 28 (2010), pp. 473-508. 
[28] Kelley, M. R. and Helper, S. "Firm Size and Capabilities, Regional Agglomeration, and the Adoption of New Technology", Economics of Innovation and New Technology, Vol. 8 (1999), pp. 79-103.

[29] Knight, D., Pearce, C. L., Smith K.G., Olian, J.D., Sims, H. P., Smith, K.A. and FloOD, P. "Top management team diversity, group process, and strategic consensus", Journal of Strategic Management, Vol. 20 (1999), pp. 445-465.

[30] Lazear, E. P. "Globalisation and the Market for Team-Mates", The Economic Journal, Vol. 109 (1999), pp. c15-c40.

[31] Maignan, C., Ottaviano, G., Pinelli, D. and Rullani F. "BioEcological Diversity vs. Socio-Economic Diversity: A Comparison of Existing Measures", Nota di Lavoro (2003), Fondazione Eni Enrico Mattei.

[32] Montgomery, James D., "Social Networks and Labor Market Outcomes: Toward an Economic Analysis," American Economic Review, 81 (1991), pp. 1408-1418.

[33] Munshi, K. "Networks in the Modern Economy: Mexican Migrants in the US Labor Market," The Quarterly Journal of Economics, Vol. 118 (2003), pp. 549-599.

[33] Niebuhr, A. "Migration and innovation: Does cultural diversity matter for regional R\&D activity?", Papers in Regional Science, 89 (2010), pp. $563-585$.

[34] OECD, "Policy responses to the Economic crisis. Investing in Innovation for Long-Term Growth", Paris, (2009).

[35] Osborne, E. "The Deceptively Simple Economics of Workplace Diversity", Journal of Labor Research, Vol. 21 (2000), pp. 463-475.

[36] Parrotta P., Pozzoli D. and Pytlikova M. "Does Labor Diversity Affect Firm Productivity?" Aarhus School of Business Working Paper No. 10-12. Aarhus. (2010).

[37] Pedersen,,J. P., Pytlikova, M. and Smith N. "Selection and Network Effects - Migration Flows into OECD Countries 1990-2000", European Economic Review. Vol. 52, Issue 7 (2008), pp. 1160-1186.

[38] Pitcher P. and Smith A.D. "Top Management Team Heterogeneity: Personality, Power, and Proxies", Organization Science, Vol. 12, No. 1 (2001), pp. 1-18.

[39] SöLlneR, R. "Human Capital Diversity and Product Innovation: A MicroLevel Analysis", Jena Economic Research Papers, (2010) - 027. 
[40] Vuong, Q. H. "Two-Stage Conditional Maximum Likelihood Estimation of Econometric Models", Social Science Working Paper, 538 (1984), California Institute of Technology.

[41] Wallsten S. J. "An Empirical Test of Geographic Knowledge Spillovers Using Geographic Information Systems and Firm-Level Data." Regional Science and Urban Economics, Vol. 31 (2001), No. 5: 571-599.

[42] Watson, W. E., Kumar K. and Michaelsen L.K. "Cultural Diversity's Impact on Interaction Process and Performance: Comparing Homogeneous and Diverse Task Groups", The Academy of Management Journal, Vol. 36, No. 3 (Jun., 1993), pp. 590-602.

[43] Williams, K.Y. and O'Reilly III. C.A."Demography and Diversity in Organizations: A Review of 40 Years of Research", In B.M. Staw \& L.L. Cummings (Eds.), Research in Organizational Behavior, Vol. 20 (1998), pp. $77-140$.

[44] Zajac E., Golden B. R. and ShorTell S. M. "New Organizational Forms for Enhancing Innovation: The Case of Internal Corporate Joint Ventures", Management Science, Vol. 37 (1991), No. 2, pp. 170-184.

[45] Østergand C. R., Timmermans B. and Kristinsson K. "Beyond Technological Diversification: The Impact of Employee Diversity on Innovation", DRUID Working Papers 09-03 (2009), DRUID, Copenhagen Business School, Department of Industrial Economics and Strategy/Aalborg University, Department of Business Studies. 


\section{Appendix 1: Measurement of ethnic diversity}

The citizens in the different nationality groups are: Danish, Danish native including second generation immigrants; North America and Oceania, United States, Canada, Australia, New Zealand; Central and South America, Guatemala, Belize, Costa Rica, Honduras, Panama, El Salvador, Nicaragua, Venezuela, Ecuador, Peru, Bolivia, Chile, Argentina, Brazil; Formerly Communist Countries, Armenia, Belarus, Estonia, Georgia, Latvia, Lithuania, Moldova, Russia, Tajikistan, Ukraine, Bulgaria, Czech Republic, Hungary, Poland, Romania, Slovakia, Albania, Bosnia and Herzegovina, Bulgaria, Croatia, Rep. of Macedonia, Montenegro, Serbia, and Slovenia; Muslim Countries, Afghanistan, Algeria, Arab Emirates, Azerbaijan, Bahrain, Bangladesh, Brunei Darussalem, Burkina Faso, Camoros, Chad, Djibouti, Egypt, Eritrea, Gambia, Guinea, Indonesia, Iran, Iraq, Jordan, Kazakstan, Kirgizstan, Kuwait, Lebanon, Libyan Arab Jamahiriya, Malaysia, Maldives, Mali, Mauritania, Morocco, Nigeria, Oman, Pakistan, Palestine, Qatar, Saudi Arabia, Senegal, Sierra Leone, Somalia, Sudan, Syria, Tadzhikstan, Tunisia, Turkey, Turkmenistan, Uzbekistan, Yemen; East Asia, China, Hong Kong, Japan, Korea, Korea Dem. People's Rep. Of, Macao, Mongolia, Taiwan; Asia, all the other Asian countries non included in both East Asia and Muslim Countries categories and Africa, all the other African countries not included in the Muslim Country; Western and Southern Europe, all the other European countries not included in the Formerly Communist Countries category.

Using linguistic grouping: Germanic West (Antigua Barbuda, Aruba, Australia, Austria, Bahamas, Barbados, Belgium, Belize, Bermuda, Botswana, Brunei, Cameroon, Canada, Cook Islands, Dominica, Eritrea, Gambia, Germany, Ghana, Grenada, Guyana, Haiti, Ireland, Jamaica, Liberia, Liechtenstein, Luxemburg, Mauritius, Namibia, Netherlands, Netherlands Antilles, New Zealand, Saint Kitts and Nevis, Saint Lucia, Saint Vincent and Grenadines, Seychelles, Sierra Leone, Solomon Islands, South Africa, St. Helena, Suriname, Switzerland, Trinidad and Tobago, Uganda, United Kingdom, United States, Zambia, Zimbabwe), Germanic Nord (Denmark, Iceland, Norway, Sweden), Slavic West (Czech Republic, Poland, Slovakia), Slavic South (Bosnia and Herzegovina, Croatia, Serbia, Slovenia), Slavic East (Belarus, Georgia, Mongolia, Russian Federation, Ukraine), Baltic East (Latvia, Lithuania), Finno-Permic 
(Finland, Estonia), Ugric (Hungary), Romance (Andorra, Angola, Argentina, Benin, Bolivia, Brazil, Burkina Faso, Cape Verde, Chile, Columbia, Costa Rica, Cote D'Ivoire, Cuba, Djibouti, Dominican Republic, Ecuador, El Salvador, Equatorial Guinea, France, French Guina, Gabon, Guadeloupe, Guatemala, Guinea, Guinea Bissau, Holy See, Honduras, Italy, Macau, Martinique, Mexico, Moldova, Mozambique, Nicaragua, Panama, Peru, Portugal, Puerto Rico, Reunion, Romania, San Marino, Sao Tome, Senegal, Spain, Uruguay, Venezuela), Attic (Cyprus, Greece), Turkic South (Azerbaijan, Turkey, Turkmenistan), Turkic West (Kazakhstan, Kyrgystan), Turkic East (Uzbekistan), Gheg (Albania, Kosovo, Republic of Macedonia, Montenegro), Semitic Central (Algeria, Bahrain, Comoros, Chad, Egypt, Irak, Israel, Jordan, Kuwait, Lebanon, Lybian Arab Jamahiria, Malta, Mauritiania, Morocco, Oman, Qatar, Saudi Arabia, Sudan, Syrian Arab Republic, Tunisia, Yemen, United Arabs Emirates), Indo-Aryan (Bangladesh, Fiji, India, Maldives, Nepal, Pakistan, Sri Lanka), Mon-Khmer East (Cambodia), Semitic South (Ethiopia), Malayo-Polynesian West (Indonesia, Philippines), Malayo-Polynesian Central East (Kiribati, Marshall Islands, Nauru, Samoa, Tonga), Iranian (Afghanistan, Iran, Tajikistan), Betai (Laos, Thailand), Malayic (Malasya), Cushitic East (Somalia), Viet-Muong (Vietnam), Volta-Congo (Burundi, Congo, Kenya, Lesotho, Malawi, Nigeria, Rwanda, Swaziland, Tanzania, Togo), Barito (Madagascar), Mande West (Mali), Lolo-Burmese (Burma), Chadic West (Niger), Guarani (Paraguay), Himalayish (Buthan), Armenian (Armenia), Sino Tibetan (China, Hong Kong, Singapore, Taiwan), Japonic (Japan, Republic of Korea, Korea D.P.R.O.).

\section{Appendix 2: External knowledge indexes}

The main literature on agglomeration economies emphasizes the importance of firm's local environment, which may reflect information advantages, labor or other inputs pooling and further beneficial network effects aimed at alleviating the burden represented by fixed costs. A seminal contribution in this field is due to Audretsch and Feldman (1996), who find that industries characterized 
by elevated R\&D intensity or particularly skilled labor forces present a greater degree of geographic concentration of production. Other relevant studies like Wallsten (2001) and Adams and Jaffe (1996) provide evidence of the geographic extent of knowledge spillovers by computing the distance in miles between each firm-pair. However, the geography is not the only dimension of the external knowledge. In fact, there exists at least another approach which focuses on the concept of technological proximity (Jaffe, 1986; Adams, 1990). Specifically, the idea that the technology developed by a firm can affect other firms, even though they are not geographically close or no transactions of goods occur between them, has led to the definition of technological proximity as closeness between firm-pairs' technological profiles.

Following both the cited approaches, we construct two indexes of knowledge spillovers. These are weighted sums of firms' codified knowledge proxied by the discounted stock of patent applications. ${ }^{19}$ The weighting function for the first index refers to the geographical distance between pairs of workplaces' municipalities and is computed by using the firms' latitude and longitude coordinates (the address of their headquarters). Specifically, assuming a spherical earth of actual earth volume, this method allows us to measure the distance in kilometers between any pair of firms $i$ and $j .{ }^{20}$ The first knowledge spillover index is then computed as follows:

$$
K \_g e o_{i t}=\frac{1}{e^{\text {dist }_{i j}}} \sum_{j \neq i}^{I} \text { disc_stock }_{j t} .
$$

The second index is instead based on the technological proximity. Following Adams (1990), we use the shares of differently skilled workers to define our

\footnotetext{
${ }^{19}$ See paragraph 4.2 .

${ }^{20}$ We use the following formula $d_{i j}=6378.7 * \operatorname{acos}\left\{\sin \left(\operatorname{lat}_{i} / 57.2958\right) * \sin \left(\operatorname{lat}_{j} / 57.2958\right)+\right.$ $+\cos \left(\right.$ lat $\left._{i} / 57.2958\right) * \cos \left(\right.$ lat $\left._{j} / 57.2958\right) * \cos \left(\right.$ lon $_{j} / 57.2958-$ lon $\left.\left._{i} / 57.2958\right)\right\}$.
} 
alternative weighting function $\psi_{i j}$ that is the uncentered correlation:

$$
\psi_{i j}=\frac{f_{i} f_{j}^{\prime}}{\left[\left(f_{i} f_{i}^{\prime}\right)\left(f_{j} f_{j}^{\prime}\right)\right]^{1 / 2}} .
$$

The components of the generator vector $f$ reflects firm's workforce composition in terms of skills using the disaggregated categorization as described in section 3.2. The second measure of knowledge spillover pool is therefore defined as

$$
K \_ \text {tech }{ }_{i t}=\psi_{i j} \sum_{j \neq i}^{I} \text { disc_stock } k_{j t} .
$$

Thus, both $K_{-} g_{e o_{i t}}$ and $K_{-} t e c h_{i j}$ contain weighting functions that might capture the so-called firm's absorptive capacity, which is the ability to identify and exploit the knowledge externally produced (Cohen and Levinthal, 1990). 


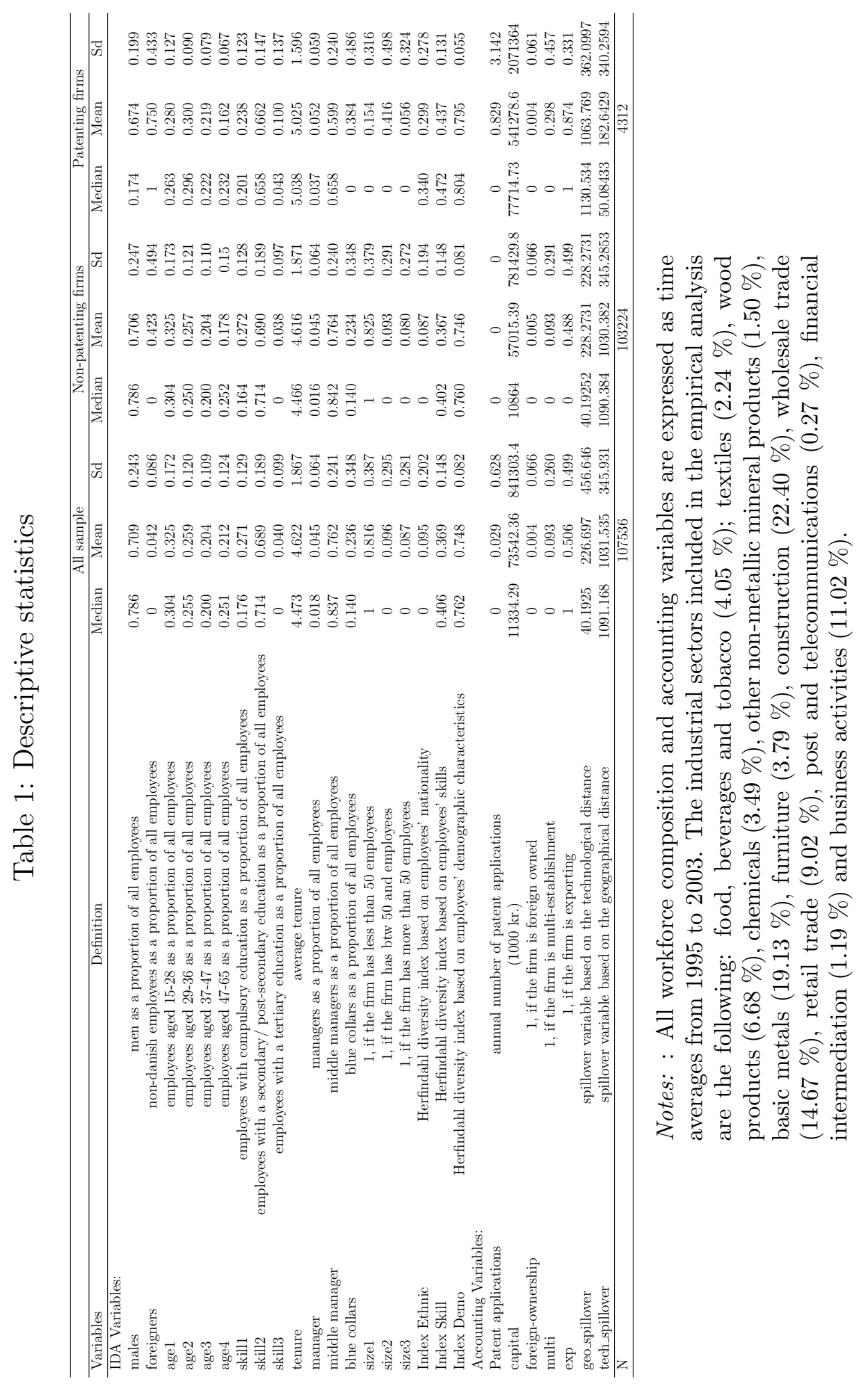




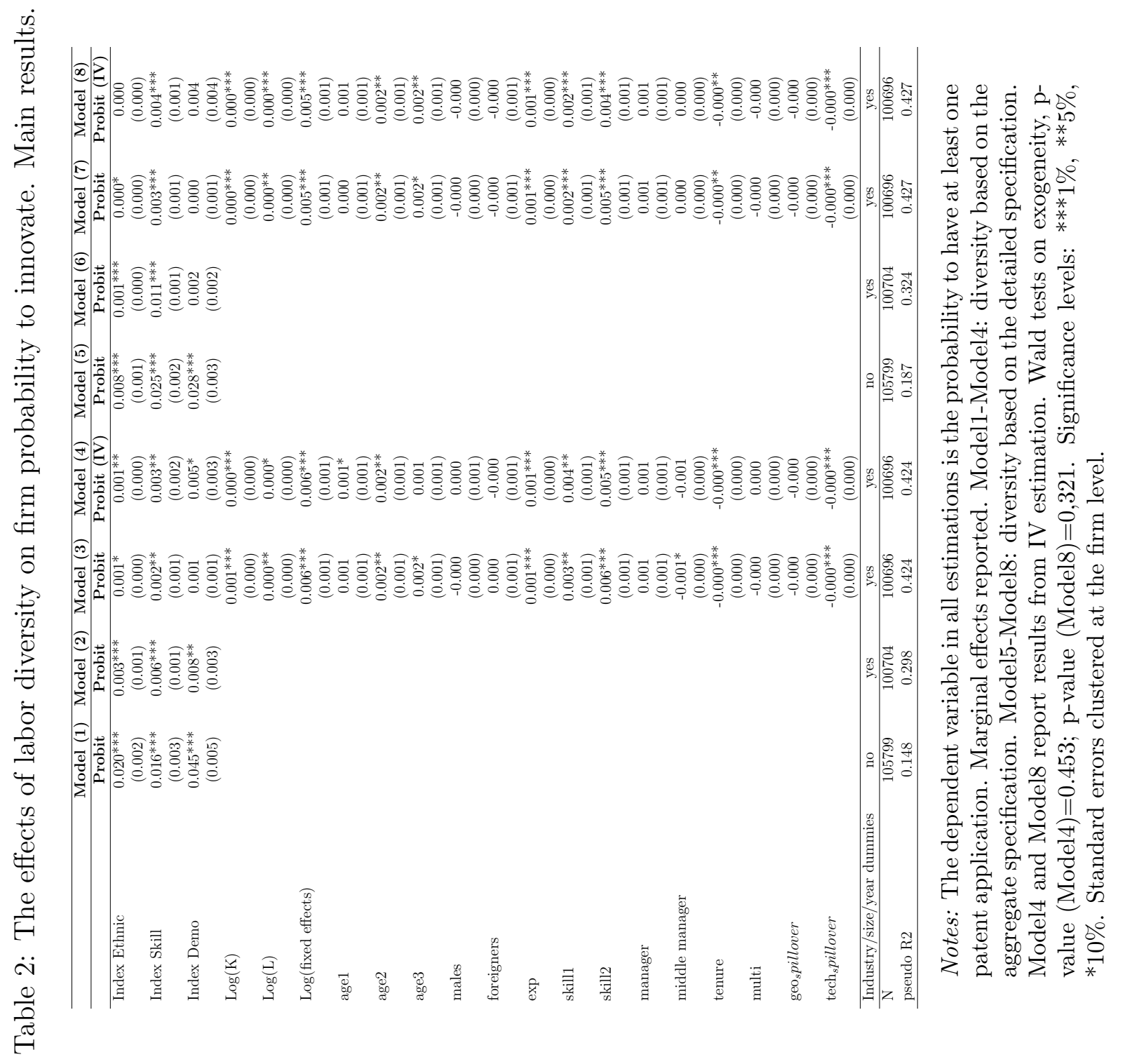




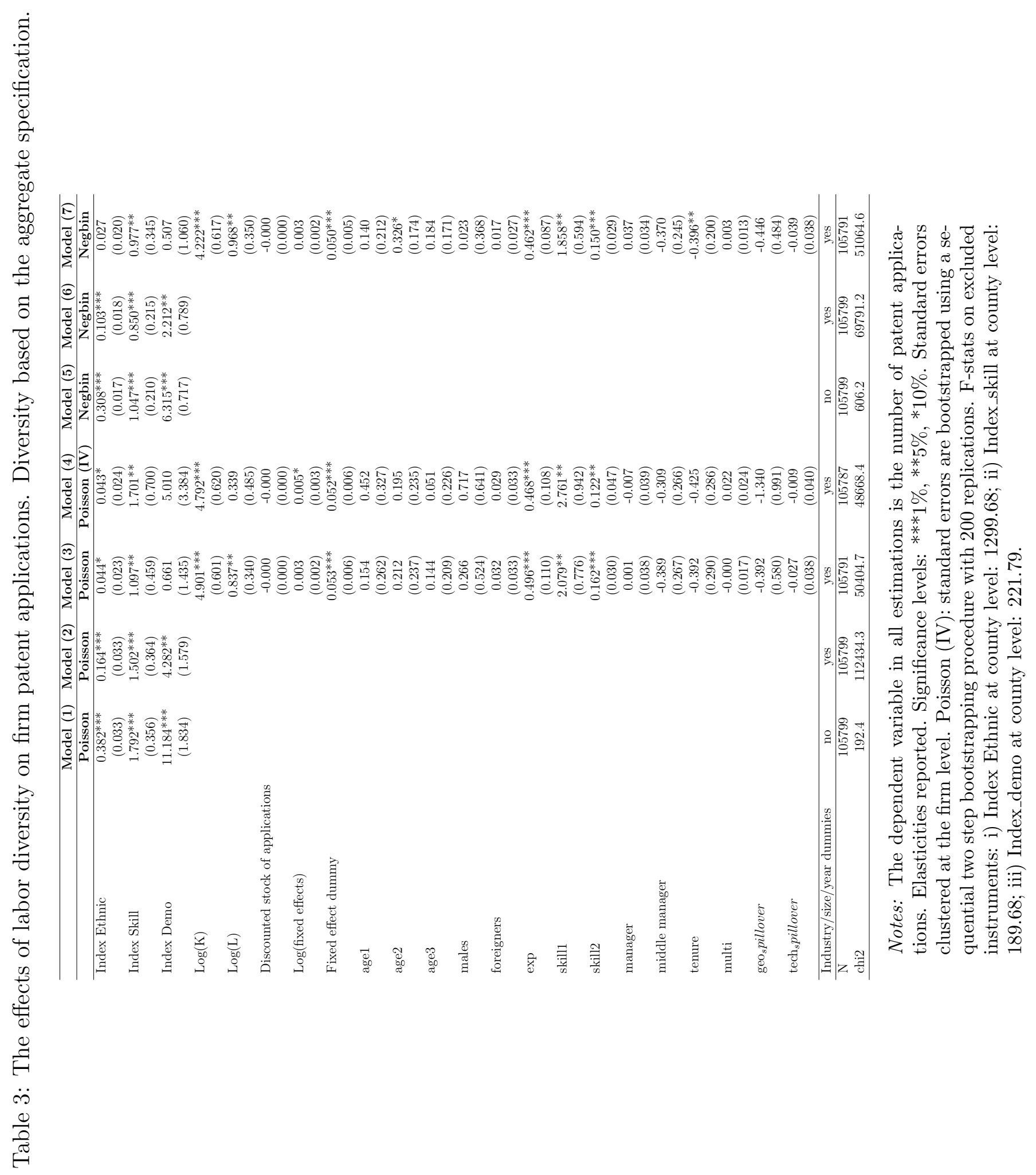




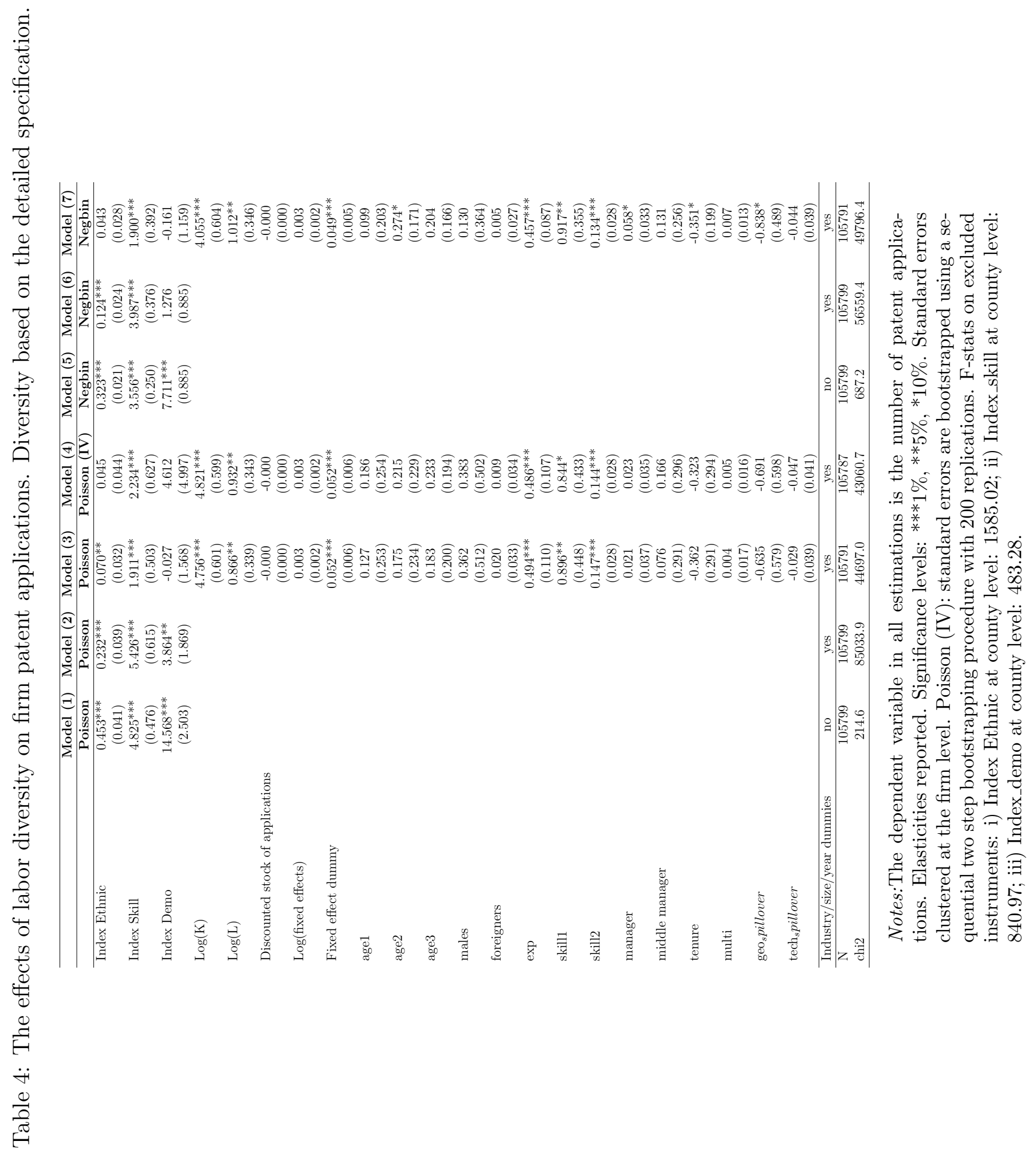


Table 5: The effects of labor diversity on the probability of applying in different technological areas.

\begin{tabular}{|c|c|c|c|c|c|c|c|c|}
\hline & Model (1) & Model (2) & Model (3) & Model (4) & Model (5) & Model (6) & Model (7) & Model (8) \\
\hline & Probit & Probit & Probit & Probit (IV) & Probit & Probit & Probit & Probit (IV) \\
\hline Index Ethnic & $0.162^{* *}$ & $0.109^{*}$ & 0.020 & 0.044 & $0.171^{* * *}$ & $0.142^{* *}$ & 0.040 & 0.050 \\
\hline & & & $(0.060)$ & $(0.060)$ & $(0.046)$ & & $(0.053)$ & $(0.065)$ \\
\hline Index Skill & $\begin{array}{c}0.572^{* * * *} \\
(0.129)\end{array}$ & $\begin{array}{c}0.563 * * * \\
(0.156)\end{array}$ & $\begin{array}{c}0.988^{* * *} \\
(0.299)\end{array}$ & $\begin{array}{c}1.412^{* * * *} \\
(0.392)\end{array}$ & $\begin{array}{c}0.821^{* * * *} \\
(0.143)\end{array}$ & $\begin{array}{c}0.809^{* * *} \\
(0.193)\end{array}$ & $\begin{array}{l}0.488^{* *} \\
(0.209)\end{array}$ & $\begin{array}{l}0.476^{* *} \\
(0.203)\end{array}$ \\
\hline Index Demo & $\begin{array}{l}0.568^{*} \\
(0.316)\end{array}$ & $\begin{array}{c}0.217 \\
(0.309)\end{array}$ & $\begin{array}{c}0.433 \\
(0.364)\end{array}$ & $\begin{array}{c}1.070 \\
(0.823)\end{array}$ & $\begin{array}{l}0.525^{*} \\
(0.316)\end{array}$ & $\begin{array}{c}0.073 \\
(0.348)\end{array}$ & $\begin{array}{c}0.299 \\
(0.370)\end{array}$ & $\begin{array}{c}0.099 \\
(1.358)\end{array}$ \\
\hline $\log (K)$ & & & $\begin{array}{l}0.030^{* * *} \\
(0.012)\end{array}$ & $\begin{array}{l}0.029^{* *} \\
(0.012)\end{array}$ & & & $\begin{array}{l}0.030^{* *} \\
(0.012)\end{array}$ & $\begin{array}{c}0.031^{* * *} \\
(0.012)\end{array}$ \\
\hline $\log (\mathrm{L})$ & & & $\begin{array}{c}0.014 \\
(0.023)\end{array}$ & $\begin{array}{l}-0.009 \\
(0.029)\end{array}$ & & & $\begin{array}{c}0.014 \\
(0.024)\end{array}$ & $\begin{array}{c}0.016 \\
(0.024)\end{array}$ \\
\hline $\log$ (fixed effects) & & & $\begin{array}{c}0.250^{* * *} \\
(0.045)\end{array}$ & $\begin{array}{c}0.278^{* * * *} \\
(0.052)\end{array}$ & & & $\begin{array}{c}0.260^{* * * *} \\
(0.046)\end{array}$ & $\begin{array}{c}0.258^{* * * *} \\
(0.046)\end{array}$ \\
\hline age1 & & & $\begin{array}{c}0.712^{* * *} \\
(0.184)\end{array}$ & $\begin{array}{c}0.800^{* * *} \\
(0.213)\end{array}$ & & & $\begin{array}{c}0.717^{* * *} \\
(0.181)\end{array}$ & $\begin{array}{c}0.758^{* * * *} \\
(0.182)\end{array}$ \\
\hline age2 & & & $\begin{array}{c}0.739^{* * * *} \\
(0.200)\end{array}$ & $\begin{array}{c}0.695^{* * *} \\
(0.202)\end{array}$ & & & $\begin{array}{c}0.696^{* * *} \\
(0.198)\end{array}$ & $\begin{array}{c}0.713^{* * *} \\
(0.202)\end{array}$ \\
\hline age3 & & & $\begin{array}{c}0.287 \\
(0.286)\end{array}$ & $\begin{array}{c}0.198 \\
(0.294)\end{array}$ & & & $\begin{array}{c}0.404 \\
(0.276)\end{array}$ & $\begin{array}{c}0.382 \\
(0.265)\end{array}$ \\
\hline males & & & $\begin{array}{c}0.143 \\
(0.099)\end{array}$ & $\begin{array}{c}0.195 \\
(0.127)\end{array}$ & & & $\begin{array}{c}0.125 \\
(0.099)\end{array}$ & $\begin{array}{c}0.125 \\
(0.098)\end{array}$ \\
\hline foreigners & & & $\begin{array}{c}0.231 \\
(0.258)\end{array}$ & $\begin{array}{c}0.175 \\
(0.257)\end{array}$ & & & $\begin{array}{c}0.189 \\
(0.274)\end{array}$ & $\begin{array}{c}0.062 \\
(0.275)\end{array}$ \\
\hline $\exp$ & & & $\begin{array}{c}0.004 \\
(0.041)\end{array}$ & $\begin{array}{c}0.001 \\
(0.040)\end{array}$ & & & $\begin{array}{c}0.016 \\
(0.042)\end{array}$ & $\begin{array}{c}0.016 \\
(0.041)\end{array}$ \\
\hline skill1 & & & $\begin{array}{c}0.731^{* *} \\
(0.253)\end{array}$ & $\begin{array}{c}1.031^{* * *} \\
(0.305)\end{array}$ & & & $\begin{array}{c}0.078 \\
(0.145)\end{array}$ & $\begin{array}{c}0.039 \\
(0.140)\end{array}$ \\
\hline skill2 & & & $\begin{array}{c}0.151 \\
(0.202)\end{array}$ & $\begin{array}{l}-0.175 \\
(0.256)\end{array}$ & & & $\begin{array}{c}0.202 \\
(0.201)\end{array}$ & $\begin{array}{c}0.109 \\
(0.206)\end{array}$ \\
\hline manager & & & $\begin{array}{c}0.171 \\
(0.214)\end{array}$ & $\begin{array}{c}0.203 \\
(0.205)\end{array}$ & & & $\begin{array}{c}0.227 \\
(0.229)\end{array}$ & $\begin{array}{c}0.277 \\
(0.229)\end{array}$ \\
\hline middle manager & & & $\begin{array}{c}0.016 \\
(0.091)\end{array}$ & $\begin{array}{c}0.035 \\
(0.090)\end{array}$ & & & $\begin{array}{c}0.064 \\
(0.100)\end{array}$ & $\begin{array}{c}0.086 \\
(0.100)\end{array}$ \\
\hline tenure & & & $\begin{array}{l}-0.003 \\
(0.010)\end{array}$ & $\begin{array}{l}-0.004 \\
(0.010)\end{array}$ & & & $\begin{array}{l}-0.004 \\
(0.010)\end{array}$ & $\begin{array}{l}-0.003 \\
(0.010)\end{array}$ \\
\hline multi & & & $\begin{array}{c}0.006 \\
(0.035)\end{array}$ & $\begin{array}{c}0.044 \\
(0.047)\end{array}$ & & & $\begin{array}{c}0.005 \\
(0.037)\end{array}$ & $\begin{array}{c}0.009 \\
(0.037)\end{array}$ \\
\hline co-patent & & & $\begin{array}{c}0.024 \\
(0.032)\end{array}$ & $\begin{array}{c}0.030 \\
(0.032)\end{array}$ & & & $\begin{array}{c}0.009 \\
(0.021)\end{array}$ & $\begin{array}{c}0.000 \\
(0.000)\end{array}$ \\
\hline geospillover & & & $\begin{array}{c}0.000 \\
(0.000)\end{array}$ & $\begin{array}{l}-0.000 \\
(0.000)\end{array}$ & & & $\begin{array}{c}0.000 \\
(0.000)\end{array}$ & $\begin{array}{l}-0.000 \\
(0.000)\end{array}$ \\
\hline tech spillover & & & $\begin{array}{c}-0.000 \\
(0.000)\end{array}$ & $\begin{array}{c}-0.000 \\
(0.000)\end{array}$ & & & $\begin{array}{l}-0.000 \\
(0.000)\end{array}$ & $\begin{array}{c}0.013 \\
(0.021)\end{array}$ \\
\hline Industry/size/year dummies & no & yes & yes & yes & no & yes & yes & yes \\
\hline & 1146 & 1116 & 1116 & 1116 & 1146 & 1116 & 1116 & 1116 \\
\hline pseudo R2 & 0.068 & 0.146 & 0.378 & 0.332 & 0.100 & 0.159 & 0.371 & 0.324 \\
\hline
\end{tabular}

Notes: The dependent variable in all estimations is the probability of applying a patent in different technological areas. Marginal effects reported. Model1-Model4: diversity based on the aggregate specification. Model5-Model8: diversity based on the detailed specification. Model4 and Model8 report results from IV estimation. Wald tests on exogeneity, p-value $($ Model4 $)=0.657$; p-value $($ Model 8$)=0.823$. Significance levels: $* * * 1 \%, * * 5 \%, 10 * \%$. Standard errors clustered at the firm level. 
Table 6: The effects of labor diversity on firm probability to innovate. Robustness checks.

\begin{tabular}{|c|c|c|c|c|c|}
\hline & $(1)$ & $(2)$ & $(3)$ & (4) & $(5)$ \\
\hline & \multicolumn{2}{|c|}{ Occupation specific diversity } & Shannon entropy index & Richness index & Grants-based definition of innovation \\
\hline & White collar & Blue collar & & & \\
\hline \multirow[t]{2}{*}{ Index Ethnic Aggr } & $0.001^{* *}$ & -0.000 & 0.000 & $0.000^{* *}$ & 0.000 \\
\hline & $(0.000)$ & $(0.000)$ & $(0.000)$ & $(0.000)$ & $(0.000)$ \\
\hline \multirow[t]{2}{*}{ Index Skill Aggr } & $0.001^{* *}$ & 0.001 & $0.001^{* *}$ & $0.001 * * *$ & $0.003^{* *}$ \\
\hline & $(0.000)$ & $(0.000)$ & $(0.000)$ & $(0.000)$ & $(0.001)$ \\
\hline \multirow{2}{*}{ Index Demo Aggr } & 0.000 & -0.000 & 0.000 & 0.000 & $0.002^{*}$ \\
\hline & $(0.000)$ & $(0.000)$ & $(0.000)$ & $(0.000)$ & $(0.001)$ \\
\hline $\mathrm{N}$ & \multicolumn{2}{|c|}{100696} & 100696 & 105791 & 100696 \\
\hline pseudo R2 & \multicolumn{2}{|c|}{0.424} & 0.425 & 0.368 & 0.646 \\
\hline Index Ethnic Disaggr & $\begin{array}{l}0.000^{*} \\
(0.000)\end{array}$ & $\begin{array}{c}0.000 \\
(0.000)\end{array}$ & $\begin{array}{c}0.000 \\
(0.001)\end{array}$ & $\begin{array}{c}0.000^{* *} \\
(0.000)\end{array}$ & $\begin{array}{l}0.000^{*} \\
(0.000)\end{array}$ \\
\hline Index Skill Disaggr & $\begin{array}{c}0.001^{* *} \\
(0.000)\end{array}$ & $\begin{array}{c}0.001^{* *} \\
(0.000)\end{array}$ & $\begin{array}{c}0.003^{*} * * \\
(0.001)\end{array}$ & $\begin{array}{c}0.001 * * * \\
(0.000)\end{array}$ & $\begin{array}{c}0.003^{* * *} \\
(0.001)\end{array}$ \\
\hline Index Demo Disaggr & $\begin{array}{c}-0.000 \\
(0.000)\end{array}$ & $\begin{array}{c}-0.000 \\
(0.000)\end{array}$ & $\begin{array}{c}0.000 \\
(0.001)\end{array}$ & $\begin{array}{c}0.000 \\
(0.000)\end{array}$ & $\begin{array}{c}0.000 \\
(0.001)\end{array}$ \\
\hline $\mathrm{N}$ & \multirow{2}{*}{\multicolumn{2}{|c|}{$\begin{array}{c}100696 \\
0.425\end{array}$}} & 100696 & 105791 & 100696 \\
\hline pseudo R2 & & & 0.425 & 0.371 & 0.427 \\
\hline
\end{tabular}

Notes: The dependent variable in all estimations is the probability to have at least one patent application. Marginal effects reported. All regressions include all the firm specific characteristics, year and three-digit industry dummies. Significance levels: $* * * 1 \%, * * 5 \%, * 10 \%$. Standard errors clustered at the firm level.

Table 7: The effects of labor diversity on firm patents. Robustness checks.

\begin{tabular}{lccccc}
\hline & $(1)$ & $(2)$ & $(3)$ & $(4)$ & $(5)$ \\
\hline & Occupation specific diversity & Shannon entropy index & Richness index & Grants-based definition of innovation \\
\hline & White collar & Blue collar & & & $0.044^{*}$ \\
Index Ethnic Aggr & $0.033^{*}$ & 0.007 & 0.099 & 0.034 & $(0.023)$ \\
& $(0.019)$ & $(0.004)$ & $(0.080)$ & $(0.022)$ & $1.097^{* *}$ \\
Index Skill Aggr & $0.422^{* *}$ & 0.065 & $0.811^{*}$ & $0.191^{* *}$ & $(0.459)$ \\
& $(0.173)$ & $(0.057)$ & $(0.445)$ & $(0.082)$ & 0.661 \\
Index Demo Aggr & -0.465 & 0.131 & 0.195 & 0.334 & $(1.435)$ \\
& $(0.427)$ & $(0.114)$ & $(0.527)$ & $(0.321)$ & 105791 \\
\hline $\mathrm{N}$ & & 105791 & 105791 & 3147.2 & 0.027 \\
chi2 & 60480.9 & 53127.0 & $0.015^{* * *}$ & $(0.020)$ \\
\hline \hline Index Ethnic Disaggr & $0.051^{* *}$ & $0.014^{*}$ & $0.090^{* *}$ & $0.977^{* *}$ \\
Index Skill Disaggr & $(0.026)$ & $(0.008)$ & $(0.041)$ & $1.003)$ & $(0.345)$ \\
& $0.739^{* * *}$ & 0.197 & $0.672^{* *}$ & $(0.186)$ & 0.507 \\
Index Demo Disaggr & $(0.193)$ & $(0.133)$ & $(0.257)$ & 0.325 & $(1.060)$ \\
& $-0.691^{*}$ & 0.074 & -0.058 & $(0.325)$ & 105791 \\
$\mathrm{~N}$ & $(0.355)$ & $(0.165)$ & $(0.461)$ & 105791 & 51064.6 \\
chi2 & \multicolumn{7}{c}{105791} & 3509.1 & \\
\hline
\end{tabular}

Notes: The dependent variable in all estimations is the probability to have at least one patent application. Elasticities reported. All regressions include all the firm specific characteristics, year and three-digit industry dummies. Significance levels: $* * * 1 \%, * * 5 \%, * 10 \%$. Standard errors clustered at the firm level. 
Figure 1: Commuting areas,1995, Denmark.

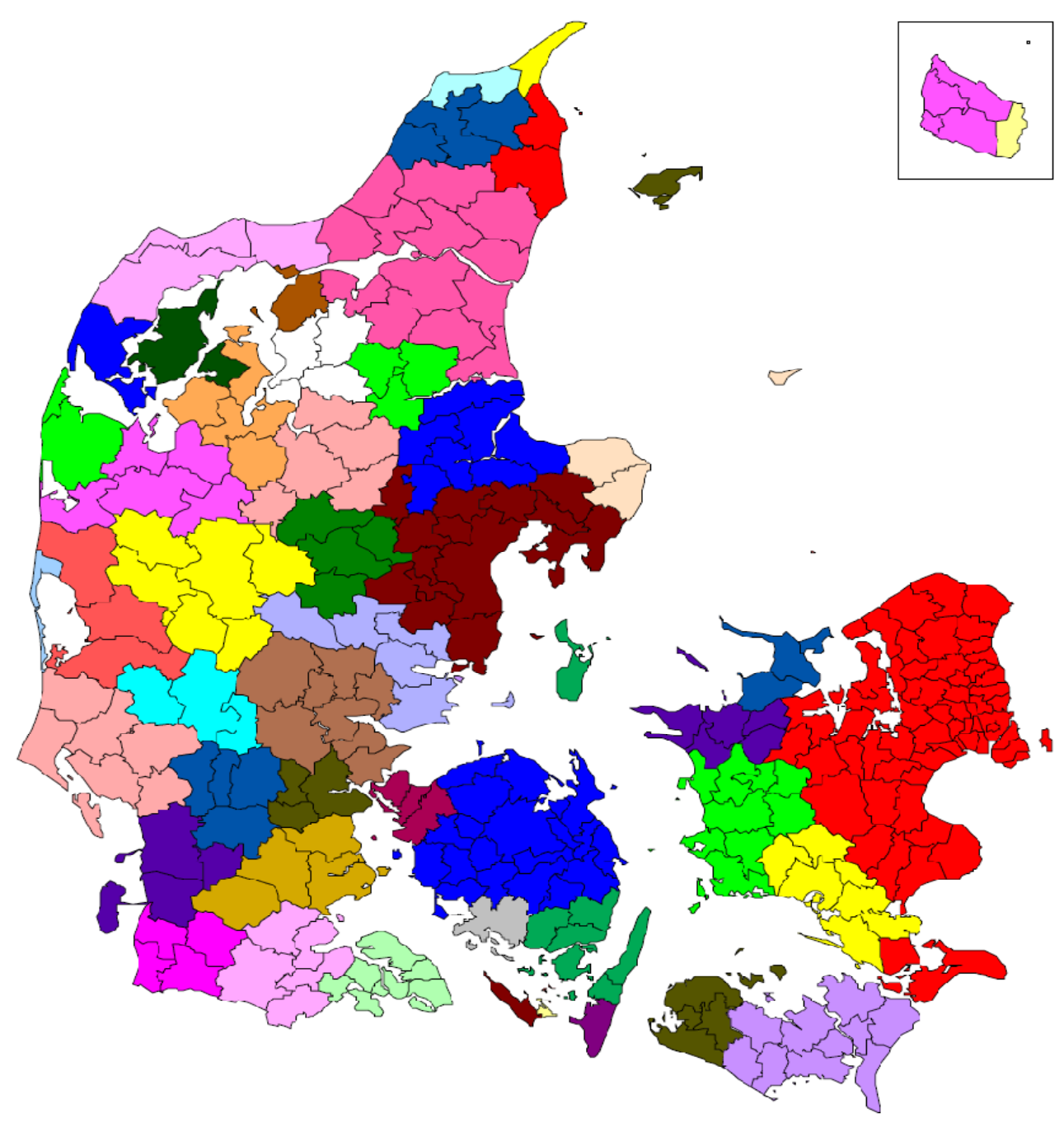

